\title{
Functional Voice Skills for Music Therapists (2018)
}

\author{
Sylka Uhlig ${ }^{1 *}$ \\ 1 HAN University, Netherlands \\ *sylka.uhlig@gmail.com
}

Received: 6 January 2019 Accepted: 7 June 2019 Published: 1 July 2019

Editor: Katrina Skewes McFerran

\section{Functional Voice Skills for Music Therapists (2018)}

By Elizabeth Schwartz, Sharon R. Boyle and Rebecca Engen. Published by Barcelona Publishers Dallas TX, USA. ISBN 978-1945411328; E-ISBN 9781945411335

This informative book is a guide for the development of functional voice skills for music therapists and students, young clinicians, educators and other health professionals in clinical settings. The book has a beautiful cover that invites the reader to take a journey through the uniqueness of the authentic voice. The authors then present techniques for developing a rich, varied, engaging, and healthy clinical voice for use in music therapy practice. They focus on the discovery of vocal challenges as well as finding personal vocal strength. The voice is described as offering myriad personal and professional opportunities for intervention and powerful reflections for therapeutic settings. The reader will read about the vocal capacity and quality of the human voice, across a range of therapeutic contexts with a focus on vocal health.

Each music therapist is invited to undertake their own personal exploration, as the individual use of the voice is considered to be unique. There is a great deal of practical information, exercises and techniques for maintaining good vocal health and supporting the expansion of each therapist's authentic voice. During this rich vocal journey, unexamined and unexplored depths may appear, and the book offers detailed descriptions of how to grow through knowledge, practice, and reflection. This collection of knowledge, experiences and techniques about the voice as a healthy clinical instrument should foster awareness and offers assurances of trust, empathy, and hope for the music therapy practice.

The book is written by three American music therapists, specialized in the voice, with the intention of educating music therapists, students and professionals about how to make the voice a clinical instrument.

Elizabeth Schwartz, is senior music therapist in New York (NY), and specialized in early intervention and preschool treatment. She developed techniques for music therapy students and professionals to find and expand their own voices. As member of the Education and Training Advisory Board to the AMTA, and frequent contributor to the Imagine early childhood music therapy magazine, she created song books with newly composed or adapted songs based in therapeutic and developmental music making in early childhood. 
Sharon R. Boyle, is Associate Professor and Coordinator of music therapy program at Saint Mary-of-the-Woods College (Indiana). As regular presenter at state, regional, and national music therapy conferences, she focusses on vocal improvisation and self-care in music therapy, and is dedicated to raising awareness of vocal health issues of music therapists. She identified environmental and habitual factors that influence vocal health, compared vocal demands and working environments with other professional voice users such as teachers for whom prevalence and causal factors are known.

Rebecca Engen, is Associate Professor and the Director of the Master of Music Therapy program at Alverno College (Wisconsin), and has published in both the Journal of Music Therapy and Music Therapy Perspectives. Her broad engagement is mirrored in her current research about the vocal health of practicing music therapists, interest in music and wellness and rehabilitation, as well as being a member of the Education and Clinical Training Advisory Board for the American Music Therapy Association (AMTA).

The book Functional Voice Skills for Music Therapists offers a useful structure for investigating each of the fifteen chapters in the same way. First, to examine the topic, which offers physiological and background facts about the voice. Second, to explore the topic, which involves creating a personal voice journal. Third, to experience the topic, which suggests regular practice of the presented concepts. Another repeating structura feature is the clinical examples provided of music therapists working within the context, and demonstrates their vocal health situations, problems and challenges - an insightful and distinctive aspect of the book.

The chapters in the book cover a wide range of vocal topics, and go beyond the regular descriptions of singing, chanting, rapping or talking in music therapy. The book opens with the historic voices of music therapists, those considered to be pioneers of the therapeutic use of the voice (Alvin, Moses, Nordoff \& Robbins, Tyson, Sokolov). It then continues with specific descriptions of Thaut's rhythmic voice qualities, Uhlig's authentic voices, and Austin's vocal psychotherapy. It presents the Baker \& Uhlig vocal qualities of voicework in music therapy, and builds from this history into an extended investigation about the importance of the development of a healthy clinical voice. The remaining fourteen chapters cover practical subjects such as mechanics, posture, breath, resonance, motor movement, as well as perception, processing and production of vocal sounds. Musical parameters of pitch, intervals, keys, melody, timbre, texture, dynamics, meter, movement, rhythm, tempo and structure are separately examined, and exercises to support practical exploration are offered. Vocalization of vowels, consonants, words and phrases, as well as techniques of articulation, speech, rhythmic speaking and chant, complete the text, and are summarized as clinical voice in action.

The intention of the book is to offer comprehensive vocal techniques that can easily be included in daily training through providing a meaningful structure for practice, along with a useful glossary and worksheets. The songs in different modes (Doirian, Phrygian, Lydian, Mixolydian, natural and harmonic minor) and the song-collection with focus on consonants, vowels, timbre, duration, articulation, tempo and meter, offer insights regarding how the voice can be explored and trained.

The book presents ways for developing healthy vocalization skills where practitioners in various clinical settings including a variety of ideas on to how to include such vocal techniques in therapy sessions with any client group. The reader is offered detailed perspectives on the human voice in ways that are easy to read and easy to practice, as well as useful for addressing vocal discomfort and challenges. The book Functional Voice Skills for Music Therapists is not only for music therapists but could be useful for music educators, community music practitioners, and any related professional, who is interested in the power, demands and opportunities of the clinical voice, far beyond learning how to sing.

\section{About the author}

Sylka Uhlig, PhD, LCAT, RMTh, NMT: Lecturer/Researcher Music Therapy \& Voice; Faculty Member of HAN University, Nijmegen, $\mathrm{PhD}$ at VU University Amsterdam, the 
Netherlands. Since 25 years experiences in music therapeutic settings in psychiatry, rehabilitation and special education. BA Music Therapy HAN University Nijmegen (1993, NL); MA Music Therapy New York University (2010, USA); PhD Music Therapy VU University Amsterdam (2019, NL). Presenter of voice workshops and trainings at international conferences, symposia and private institutions; author of books and articles about music, emotion, voice and voicework in Music Therapy; founder of Voice Forum. http://sylkauhlig.com/ 